\title{
LIDERANÇA E COMUNICAÇÃO: ESTRATÉGIAS ESSENCIAIS PARA O GERENCIAMENTO DA ASSISTÊNCIA DE ENFERMAGEM NO CONTEXTO HOSPITALAR*
}

\author{
Cristina Maria Galvão** \\ Namie Okino Sawada*** \\ Adélia Paula de Castro**** \\ Fabiana Corniani*****
}

GALVÃO, C.M.; SAWADA, N.O.; CASTRO, A.P. de; CORNIANI, F. Liderança e comunicação: estratégias essenciais para o gerenciamento da assistência de enfermagem no contexto hospitalar. Rev.latino-am.enfermagem, Ribeirão Preto, v. 8, n. 5, p. 34-43, outubro 2000.

A liderança e a comunicação são estratégias que possibilitam ao enfermeiro promover a melhoria do gerenciamento da assistência de enfermagem no contexto hospitalar. O presente estudo teve como objetivos relatar um programa de Educação Continuada desenvolvido com enfermeiros de um hospital privado sobre liderança e comunicação e apresentar a aplicação da Liderança Situacional na prática profissional destes profissionais. A técnica dos incidentes críticos foi empregada para a coleta dos dados. Os sujeitos participantes do estudo avaliaram positivamente as contribuições oriundas do programa, constatamos também a viabilidade de aplicação da Liderança Situacional no cotidiano da enfermagem.

UNITERMOS: liderança, comunicação, educação contínua em enfermagem

\section{1 - INTRODUÇÃO}

Na enfermagem brasileira, vários são os estudos que abordam a importância da liderança e da comunicação para o enfermeiro desenvolver o gerenciamento da assistência de enfermagem prestada ao paciente/cliente, dentre eles, destacamos os trabalhos de GALVÃO ${ }^{6}$; TREVIZAN $^{17} ; \operatorname{MENDES}^{13}$ e SILVA $^{16}$.

Segundo GALVÃO ${ }^{5}$ "é através da liderança que o enfermeiro tenta conciliar os objetivos organizacionais com os objetivos do grupo da enfermagem, buscando o aprimoramento da prática profissional e principalmente o alcance de uma assistência de enfermagem adequada". Concordamos com TREVIZAN et al. ${ }^{18}$ que "no âmago da liderança está a capacidade de comunicar. Assim, a comunicação é fundamental para o exercício da influência, para a coordenação das atividades grupais e, portanto para a efetivação do processo de liderança”.

Ao nos reportarmos para a prática profissional, no contexto hospitalar, fundamentadas em nossa experiência e nos estudos de FÁVERO ${ }^{3}$ e FERRAZ ${ }^{4}$, entendemos que a gerência exercida pelo enfermeiro está mais orientada para as necessidades da organização, reproduzindo o que é preconizado nesta e por outros profissionais da área da saúde, ressaltada aqui a equipe médica. Muitas vezes esta forma de gerenciar contribui para o não atendimento das necessidades reais do paciente, gera conflitos e insatisfações na equipe de enfermagem.

Frente ao exposto, acreditamos que o enfermeiro deve desempenhar uma gerência inovadora, buscando meios que possibilitem a melhoria da qualidade da assistência de enfermagem, maior satisfação para a equipe de enfermagem, bem como o alcance dos objetivos organizacionais. Nesse cenário, a liderança e a comunicação, ao nosso ver, consistem em estratégias fundamentais para implementar as mudanças necessárias na forma atual de gerenciar do enfermeiro.

\footnotetext{
* Trabalho subvencionado pelo Conselho Nacional de Desenvolvimento Científico e Tecnológico/CNPq (Processo 520290/97-6)

** Professor Doutor do Departamento de Enfermagem Geral e Especializada da Escola de Enfermagem de Ribeirão Preto da Universidade de São Paulo. Coordenadora/Pesquisadora do Projeto Integrado de Pesquisa

*** Professor Doutor do Departamento de Enfermagem Geral e Especializada da Escola de Enfermagem de Ribeirão Preto da Universidade de São Paulo. Pesquisadora do Projeto Integrado de Pesquisa

**** Enfermeira. Bolsista de Aperfeiçoamento do Projeto Integrado de Pesquisa

***** Discente do curso de graduação da Escola de Enfermagem de Ribeirão Preto-USP. Bolsista de Iniciação Científica do Projeto Integrado de Pesquisa
} 
Partindo da premissa de que a liderança pode e deve ser aprendida pelo enfermeiro, entendemos que o preparo em liderança deste profissional seja essencial para a sua prática diária. A busca de meios que viabilizem o desenvolvimento da habilidade de liderar do enfermeiro é fundamental, assim, salientamos o embasamento teórico e a comunicação.

Entendemos que o embasamento teórico, consiste no eixo norteador do processo de capacitação do enfermeiro-líder e a comunicação um instrumento crucial no processo de liderança. A comunicação é um recurso que permite ao líder aproximar-se dos liderados com o intuito de compreender as atividades de cada um, compartilhar idéias e visões, bem como criar interdependências para o desenvolvimento do trabalho através de equipes.

Para fundamentarmos a presente investigação selecionamos o modelo proposto por HERSEY \& BLANCHARD $^{9}$ denominado Liderança Situacional, o qual foi desenvolvido na enfermagem norte americana por HERSEY \& DULDT ${ }^{10}$.

O conceito básico da Liderança Situacional consiste na premissa de que não existe um único estilo de liderança apropriado para toda e qualquer situação. $\mathrm{O}$ líder, liderados e a situação são as variáveis norteadoras do processo de liderança; entretanto, neste modelo a ênfase recai sobre o comportamento do líder em relação aos liderados frente a uma tarefa específica.

A presente investigação pretende focalizar a contribuição que a Liderança Situacional poderá propiciar ao enfermeiro líder. Apesar de restrições que o modelo possa oferecer acreditamos que o seu conhecimento, a sua compreensão e a sua aplicação constituem um dos caminhos para viabilizarmos o aprendizado sobre a liderança.

KOUZES \& POSNER ${ }^{11}$, estudiosos da temática liderança, identificaram três oportunidades principais para aprender a liderar, são elas: tentativa e erro, que refere-se a forma de aprendizado baseada na experiência profissional; observação dos outros, aprender a partir das experiências oriundas do convívio com líderes que admiramos ou não; estudo através da educação formal e treinamento.

No contexto da enfermagem, nas instituições de saúde, a Educação Continuada é utilizada como mecanismo para o desenvolvimento de recursos humanos e da instituição. Concordamos com KURCGANT ${ }^{12}$, ao analisar que "a Educação Continuada pode ter significado de desenvolver o indivíduo para fazer melhor aquilo que ele já faz, enfocando especificamente o "como fazer" e referendando o "status quo" ou o de preparar o indivíduo para atuar na realidade do momento, mas principalmente para o futuro". A autora salienta que este último significado seria o mais apropriado, uma vez que capacitaria o indivíduo para as mudanças cada vez mais rápidas e complexas, dentre elas, ressaltamos o surgimento de novas tecnologias.

Segundo PIMENTEL ${ }^{15}$ "a Educação Continuada permite enfrentar e resolver corretamente os problemas, proporcionando serviços eficientes e eficazes".

Assim, a presente investigação tem como objetivos:

- relatar a elaboração, implementação e avaliação de um programa de Educação Continuada sobre liderança e comunicação realizado com enfermeiros de um hospital privado;

- apresentar a aplicação da Liderança Situacional desenvolvida pelos participantes do programa de Educação Continuada.

\section{2 - PROGRAMA DE EDUCAÇÃO CONTINUADA}

Passaremos a descrever as etapas do programa de Educação Continuada:

\section{1- Elaboração do programa}

No primeiro semestre de 1998, as autoras deste estudo marcaram uma entrevista com a enfermeira responsável pela gerência de enfermagem do hospital investigado para apresentarmos a proposta de realização de um programa de Educação Continuada abordando a temática liderança e comunicação para os enfermeiros que atuavam naquela instituição.

$\mathrm{Na}$ ocasião a referida enfermeira mostrou-se interessada pois, o setor de recursos humanos estava desenvolvendo um programa para melhorar a forma de atuação dos enfermeiros como gerentes e a temática proposta vinha de encontro com as expectativas da organização. Entretanto, a operacionalização do programa só seria possível após consentimento e avaliação do setor de treinamento, seleção e Educação Continuada.

Uma nova reunião foi agendada com o diretor administrativo, a psicóloga e a enfermeira que atuavam no setor específico; nesta a proposta do programa foi novamente apresentada. Após avaliação sobre a viabilidade do programa recebemos resposta positiva, entretanto, ele só poderia ser realizado no segundo semestre do ano corrente devido a programação de outros eventos já estabelecida.

No final do semestre realizamos uma reunião com a psicóloga e a enfermeira do setor de treinamento, seleção e Educação Continuada para discutirmos o conteúdo e as estratégias que seriam empregadas no 
programa; estas profissionais fizeram sugestões de mudanças, as quais acatamos para não ocorrer repetição de conteúdo já abordado em outros programas e tornar o processo de ensino-aprendizagem dinâmico e orientado para as necessidades reais dos enfermeiros.

\section{2- Implementação e avaliação do programa}

O programa de Educação Continuada foi realizado no mês de agosto de 1998; nos dias 18 e 19 para o grupo A constituído de doze enfermeiros e nos dias 24 e 25 para o grupo B constituído de vinte enfermeiros. Houve a necessidade de ministrarmos o programa para dois grupos distintos de profissionais devido a disponibilidade de horário destes; assim, trinta e dois sujeitos participaram nesta etapa do programa.

O programa foi implementado em duas fases: a primeira consistiu na parte teórica, ou seja, a ministração do conteúdo proposto, perfazendo uma carga horária de oito horas; na segunda foi realizado a aplicação dos pressupostos teóricos desenvolvidos na fase anterior com carga horária de duas horas.

Em relação a primeira fase de implementação do programa, no primeiro período (4 horas) foi ministrado conteúdo sobre liderança, a saber: conceito, evolução histórica, habilidades do líder e importância da liderança no contexto da enfermagem; a seguir foi solicitado aos enfermeiros que respondessem um instrumento o qual permite detectar o perfil de líder de cada profissional. Após discussão das respostas oriundas do instrumento, passamos a apresentar os principais conceitos do modelo de Liderança Situacional proposto por HERSEY \& BLANCHARD $^{9}$. O último tópico abordado neste período foi demonstrar através de exemplos como o enfermeiro pode aplicar este modelo no desenvolvimento de seu trabalho diário com a equipe de enfermagem.

No segundo período (4 horas), a temática comunicação foi abordada, dentre os tópicos ressaltamos: conceito e principais elementos, tipos de comunicação verbal e não verbal. Salientamos que o conteúdo foi ministrado através de aulas dialogadas, nas quais procuramos incentivar a participação dos enfermeiros, os quais colocavam suas dúvidas como também as experiências profissionais vivenciadas que possibilitaram o enriquecimento do conteúdo proposto.

Para finalizar a fase teórica do programa, através de músicas e um texto elaborado realizamos uma discussão sobre a importância da comunicação para a eficácia do processo de liderança.

A seguir, solicitamos que os enfermeiros respondessem um instrumento de avaliação desta fase do programa. $\mathrm{O}$ instrumento abordava aspectos relativos ao conteúdo e duração do programa, desempenho dos instrutores e material didático.

Nestes aspectos os sujeitos deveriam assinalar uma escala de pontuação para cada item (ótimo - bom razoável - insatisfatório), sendo que a maioria dos enfermeiros do grupo A responderam ótimo para os itens analisados e os do grupo B responderam bom.

Além dos aspectos acima referidos, o instrumento continha questões abertas sobre os pontos positivos e os que deveriam melhorar no programa, bem como quais as contribuições que este trouxe para a prática profissional dos enfermeiros.

Em relação aos pontos positivos, dentre todos que os enfermeiros responderam salientamos: “o programa proporcionou maior conhecimento sobre a temática em questão; reflexões sobre a prática profissional, principalmente na utilização da liderança e comunicação com os liderados (equipe de enfermagem); maior interação entre os enfermeiros que atuam no hospital e a viabilidade de aplicação do conhecimento adquirido no desenvolvimento do trabalho diário".

Um período maior para a discussão da experiência profissional do grupo; como também a apresentação de situações do dia a dia, nas quais o conhecimento abordado pudesse ser aplicado; bem como o aumento da carga horária e do conteúdo programático foram os pontos apontados pelos enfermeiros que deveriam se revistos.

Dentre as contribuições decorrentes do programa para prática profissional relacionadas pelos enfermeiros ressaltamos: "a melhoria do desempenho em liderança através da comunicação; reflexões sobre a forma de liderar e comunicar-se com a equipe de enfermagem; utilização da liderança e comunicação para promover mudanças com vistas a melhoria da assistência de enfermagem, do relacionamento com os liderados e incrementar o potencial pessoal e profissional da equipe de enfermagem".

\section{3 - APLICAÇÃO DA LIDERANÇA SITUACIONAL NA PRÁTICA PROFISSIONAL DO ENFERMEIRO NO CONTEXTO HOSPITALAR}

\section{1- Procedimento metodológico}

Durante a primeira fase do programa informamos 
aos participantes que teríamos uma fase posterior, na qual agendaríamos encontros para discutirmos a aplicação dos conceitos-chave da Liderança Situacional, solicitamos também a leitura prévia do artigo GALVÃO et al. ${ }^{7}$, o qual fez parte do material didático elaborado.

A técnica dos incidentes críticos foi empregada para o alcance do segundo objetivo desta investigação. Esta técnica foi proposta pela primeira vez pelo Dr. John C. Flanagan como resultado de estudos no Programa de Psicologia da Aviação da Força Aérea dos Estados Unidos da América na II Grande Guerra (1941).

No Brasil, no início da década de 70, a técnica em questão foi introduzida por DELA COLETA ${ }^{2}$, de acordo com este autor esta técnica é um método indireto de análise do trabalho.

Para a coleta dos incidentes críticos elaboramos um instrumento, o qual contém uma questão sobre a utilização dos conceitos-chave da Liderança Situacional na prática diária do enfermeiro (Anexo A).

No mês de setembro, pelo correio, foi enviado a todos os participantes da primeira fase do programa o instrumento acima referido, o qual deveria ser preenchido pelo enfermeiro e discutido nos encontros agendados.

Os encontros com os enfermeiros ocorreram nos meses de outubro e novembro, totalizando três com duração em média de duas horas em cada encontro.

No início de cada encontro resgatamos os conceitos-chave da Liderança Situacional e situações do dia a dia que poderíamos aplicar este modelo.

Os enfermeiros relataram experiências vivenciadas após a participação no programa de Educação Continuada, nas quais o modelo em questão poderia ser utilizado.

A seguir, as dúvidas em relação ao preenchimento do instrumento foram mencionados pelos enfermeiros e solucionadas pelas pesquisadoras. $\mathrm{O}$ recolhimento do instrumento foi realizado em data posterior.

Assim, dos trinta e dois enfermeiros que participaram da primeira fase do programa de Educação Continuada, vinte e quatro responderam o instrumento sobre a aplicação da Liderança Situacional na prática profissional.

Após realizarmos o recolhimento dos instrumentos, procedemos a análise dos incidentes críticos descritos pelos enfermeiros participantes do estudo.

Em relação aos aspectos éticos para o desenvolvimento da presente pesquisa, conforme mencionamos anteriormente, recebemos consentimento da instituição de saúde para a realização do programa de Educação Continuada, como também consentimento verbal dos sujeitos participantes; na ocasião informamos que os dados seriam mantidos em sigilo.

\section{2- Caracterização da amostra}

$\mathrm{Na}$ amostra, todos os sujeitos eram do sexo feminino; um $(4,1 \%)$ encontrava-se na faixa etária de vinte a vinte e quatro anos, doze $(50 \%)$ na faixa etária de vinte e cinco a trinta anos, três $(12,5 \%)$ na faixa etária de trinta e um a trinta e cinco anos, seis $(25 \%)$ na faixa etária de trinta e seis a quarenta anos e dois $(8,3 \%)$ na faixa etária de quarenta e um a quarenta e cinco anos.

Dos sujeitos investigados, quatro $(16,6 \%)$ graduaram-se em instituições de ensino particular e vinte $(83,3 \%)$ em instituições públicas.

Em relação ao local de trabalho dos enfermeiros, um $(4,1 \%)$ era responsável pela chefia de enfermagem, seis $(25 \%)$ atuavam em unidades especializadas, tais como: Centro Cirúrgico, Central de Material, Recuperação Pós-Anestésica e Cirurgia Ambulatorial, nove $(37,5 \%)$ trabalhavam em unidades de internação, quatro $(16,6 \%)$ no berçario e unidade de terapia intensiva neonatal e quatro $(16,6 \%)$ em unidade de pronto atendimento e urgência.

Dos enfermeiros participantes, cinco $(20,8 \%)$ atuavam no seu local de trabalho no período de um mês a um ano, dez $(41,6 \%)$ no período de um a cinco anos, sete $(29,1 \%)$ no período de seis a dez anos e dois $(8,3 \%)$ no período de onze a quinze anos.

\section{3- Descrição e análise dos resultados}

Os enfermeiros investigados descreveram vinte e nove incidentes críticos. Para DELA COLETA ${ }^{2}$, incidentes críticos "são as situações, particularmente relevantes, observadas e relatadas pelos sujeitos entrevistados. Podem ser positivos ou negativos, em função de suas conseqüências para com os objetivos delimitados". De cada incidente crítico descrito pelos participantes do estudo identificamos as situações, comportamentos e conseqüências.

Ressaltamos que, segundo NOGUEIRA ${ }^{14}$ compreendemos por "situação o tipo de fato ou circunstância que levou o sujeito a emitir determinado comportamento, por comportamento entendemos a conduta apresentada pelo sujeito devido a circunstância, e por conseqüência, o resultado do comportamento do sujeito devido a circunstância”.

Após identificarmos as situações, comportamentos e conseqüências extraídos dos incidentes críticos, agrupamos os dados em categorias para possibilitar a análise. Assim, as situações foram agrupadas em nove categorias (Quadro 1), os comportamentos em doze categorias (Quadro 2) e as conseqüências em seis categorias (Quadro 3). 
Quadro 1 - Distribuição das categorias das situações descritas pelos enfermeiros e a freqüência com que ocorreram. Ribeirão Preto, 1998

\begin{tabular}{|c|c|c|}
\hline $\mathbf{n}^{0}$ & Sìuação & $\begin{array}{l}\text { Incidente crítico } \\
\text { (frequêtecia) }\end{array}$ \\
\hline 1 & $\begin{array}{l}\text { Necessidade de atendimento do } \\
\text { paciente }\end{array}$ & 3 \\
\hline 2 & $\begin{array}{l}\text { Dificuldade na elaboração de escalas } \\
\text { (mensal, folga e férias) }\end{array}$ & 3 \\
\hline 3 & $\begin{array}{l}\text { Necessidade de execução de } \\
\text { procedimento }\end{array}$ & 6 \\
\hline 4 & $\begin{array}{l}\text { Necessidade de realizar atividades } \\
\text { assistenciais concormitantes }\end{array}$ & 3 \\
\hline 5 & Falta de recursos materiais & 2 \\
\hline 6 & $\begin{array}{l}\text { Dificuldade de relacionamento entre os } \\
\text { integrantes da equipe de enfermagem }\end{array}$ & 4 \\
\hline 7 & $\begin{array}{l}\text { Implementação de nova rotina no } \\
\text { serviço }\end{array}$ & 4 \\
\hline 8 & Conduta profissional inadequada & 3 \\
\hline 9 & Falta no serviço & 1 \\
\hline \multicolumn{2}{|c|}{ Total } & 29 \\
\hline
\end{tabular}

Quadro 2 - Distribuição das categorias dos comportamentos dos enfermeiros e a freqüência com que ocorreram. Ribeirão Preto, 1998

\begin{tabular}{|c|c|c|}
\hline$n^{0}$ & Situação & $\begin{array}{l}\text { Incidente crítico } \\
\text { (freqüềncia) }\end{array}$ \\
\hline 1 & $\begin{array}{l}\text { Orienta sobre o que fazer, cuardo ecomo } \\
\text { frente a determinada situação }\end{array}$ & 2 \\
\hline 2 & $\begin{array}{l}\text { Orienta a forma adequada de execução } \\
\text { do procedimento }\end{array}$ & 6 \\
\hline 3 & $\begin{array}{l}\text { Direciona o trabalho a ser deservolvido } \\
\text { pela equipe de enfermagem }\end{array}$ & 6 \\
\hline 4 & $\begin{array}{l}\text { Delega a resolução do problema para a } \\
\text { equipe de enfermagem }\end{array}$ & 6 \\
\hline 5 & $\begin{array}{l}\text { Ouve a equipe de enfermagem sobre os } \\
\text { problemas pessoais e profis sionais } \\
\text { enfrentados na unidade }\end{array}$ & 3 \\
\hline 6 & $\begin{array}{l}\text { Discute os problems de relacionamento } \\
\text { com a equipe de enfermagem }\end{array}$ & 3 \\
\hline 7 & $\begin{array}{l}\text { Tenta promover mudanças no } \\
\text { comportamento do rermbro da equipe de } \\
\text { enfermagem }\end{array}$ & 2 \\
\hline 8 & $\begin{array}{l}\text { Promove mudanças no espaço fisico e } \\
\text { rotinas do serviço }\end{array}$ & 1 \\
\hline 9 & $\begin{array}{l}\text { Discute a distrbuição das atividades na } \\
\text { unidade com a equipe de enfermagem }\end{array}$ & 4 \\
\hline 10 & $\begin{array}{l}\text { Avalia o desempenho do membro da } \\
\text { equipe de enfermagem frente a execução } \\
\text { de urm procedimento }\end{array}$ & 6 \\
\hline 11 & $\begin{array}{l}\text { Explica a elaboração de escalas (mensal, } \\
\text { folga e férias) }\end{array}$ & 2 \\
\hline 12 & $\begin{array}{l}\text { Avalia a resolução do problema } \\
\text { solucionado pelo integrante da equipe de } \\
\text { enfermagem }\end{array}$ & 3 \\
\hline \multicolumn{2}{|l|}{ Total } & 44 \\
\hline
\end{tabular}

Quadro 3 - Distribuição das categorias das conseqüências dos comportamentos dos enfermeiros e a freqüência com que ocorreram. Ribeirão Preto, 1998

\begin{tabular}{|c|c|c|}
\hline$n^{0}$ & Sïuação & $\begin{array}{l}\text { Incidente crítico } \\
\text { (fiequîencia) }\end{array}$ \\
\hline 1 & Resolução do problema & 9 \\
\hline 2 & Execução do procedimento & 4 \\
\hline 3 & $\begin{array}{l}\text { Realização da assistência de } \\
\text { enfermagem }\end{array}$ & 16 \\
\hline 4 & $\begin{array}{l}\text { Melhoria da produtividade do trabalho } \\
\text { da equipe de enfermagern }\end{array}$ & 10 \\
\hline 5 & $\begin{array}{l}\text { Implementação adequada de nova } \\
\text { rotina na unidade }\end{array}$ & 4 \\
\hline 6 & $\begin{array}{l}\text { Demissão do membro da equipe de } \\
\text { enfermagern }\end{array}$ & 1 \\
\hline \multicolumn{2}{|c|}{ Total } & 44 \\
\hline
\end{tabular}

Passaremos a discorrer sobre os comportamentos dos enfermeiros, suas conseqüências em cada situação específica.

O comportamento dos enfermeiros que obteve maior freqüência na situação necessidade de atendimento do paciente foi orienta sobre o que fazer, quando e como frente a determinada situação. As conseqüências relativas a esse comportamento foram: realização da assistência de enfermagem e resolução do problema.

Ao nos reportamos a Liderança Situacional o comportamento adotado pelos sujeitos refere-se ao estilo de liderança determinar $\left(\mathrm{E}_{1}\right)$. Este estilo é apropriado para liderados com nível de maturidade baixo $\left(\mathrm{M}_{1}\right)$; geralmente pessoas que não têm capacidade e nem disposição para assumirem determinada tarefa; em outras palavras, liderado recém admitido no serviço ou que ainda nunca desenvolveu aquela atividade específica.

No estilo determinar $\left(\mathrm{E}_{1}\right)$ o comportamento do líder é diretivo. Assim, o enfermeiro ao utilizar este estilo deverá orientar o membro da equipe de enfermagem de forma clara e objetiva e promover uma supervisão rigorosa; este profissional define a atividade que deve ser feita, como, quando e onde executá-la.

Na situação dificuldade de elaboração de escalas, (mensal, folga e férias) o comportamento dos enfermeiros explica a elaboração de escalas apresentou maior freqüência e a conseqüência resultante foi resolução do problema.

Ao adotarem este comportamento, entendemos que os sujeitos participantes do estudo utilizaram o estilo de liderança persuadir $\left(\mathrm{E}_{2}\right)$ que é o mais indicado para liderado com nível de maturidade baixo a moderado $\left(\mathrm{M}_{2}\right)$, ou seja, não tem capacidade mas sente disposição em assumir responsabilidades.

Apesar do comportamento do líder ainda ser 
diretivo, ele através da comunicação bilateral apoia e encoraja o liderado a adotar o comportamento desejado, geralmente o liderado acata as decisões do líder após compreender a razão destas.

O comportamento dos enfermeiros orienta a forma adequada de execução do procedimento foi o que ocorreu com maior freqüência na situação necessidade de execução de procedimento. As conseqüências decorrentes destes comportamento foram: execução do procedimento e realização da assistência de enfermagem.

Em segundo lugar ficou o comportamento dos enfermeiros avalia o desempenho do membro da equipe de enfermagem frente a execução de um procedimento, as conseqüências foram as mesmas do comportamento mencionado anteriormente.

HERSEY \& BLANCHARD ${ }^{9}$ ressaltam que o ponto chave para o uso da Liderança Situacional com sucesso consiste no reconhecimento do nível de maturidade do liderado em relação a determinada tarefa, assim ao nos reportarmos aos comportamentos dos enfermeiros descritos, entendemos que estes profissionais adotaram os estilos determinar $\left(E_{1}\right)$ ou persuadir $\left(E_{2}\right)$ pois, estes estilos envolvem comportamento diretivo por parte do líder.

Na situação necessidade de realizar atividades assistenciais concomitantes, dois comportamentos dos enfermeiros obtiveram maior freqüência, a saber: direciona o trabalho a ser desenvolvido pela equipe de enfermagem e discute a distribuição das atividades na unidade com a equipe de enfermagem; a conseqüência relativa a estes comportamentos foi realização da assistência de enfermagem.

Em relação ao primeiro comportamento dos enfermeiros já descrito, acreditamos que os sujeitos adotaram também os estilos de liderança determinar $\left(E_{1}\right)$ ou persuadir $\left(\mathrm{E}_{2}\right)$, entretanto, ao analisarmos o segundo comportamento descrito podemos afirmar que o estilo de liderança utilizado foi o compartilhar $\left(\mathrm{E}_{3}\right)$. Este estilo é adequado para liderado com nível de maturidade entre moderado a alto $\left(\mathrm{M}_{3}\right)$, esta pessoa tem capacidade mas não está disposta a fazer o que o líder quer, assim o enfermeiro necessita encorajar o membro da equipe de enfermagem a usar a capacidade que já possui.

O estilo compartilhar $\left(\mathrm{E}_{3}\right)$ é participativo "porque o líder e o liderado participam juntos da tomada de decisão, sendo o papel principal do líder facilitar a tarefa e a comunicação"."

Na situação dificuldades de relacionamento entre os integrantes da equipe de enfermagem foi o comportamento dos enfermeiros discute os problemas de relacionamento com a equipe de enfermagem que obteve maior freqüência; as conseqüências deste foram: resolução do problema e melhoria da produtividade do trabalho da equipe de enfermagem.

Em segundo lugar, nesta situação, ficou o comportamento dos enfermeiros ouve a equipe de enfermagem sobre os problemas pessoais e profissionais enfrentados na unidade, as conseqüências foram as mesmas do comportamento mencionado anteriormente.

Ao nos reportamos a Liderança Situacional nesta situação específica, entendemos que os sujeitos investigados adotaram o estilo de liderança compartilhar $\left(\mathrm{E}_{3}\right)$ já mencionado.

Salientamos aqui, a importância da comunicação para a eficácia do processo de liderar. Para DECRANE JUNIOR $^{1}$ o líder do futuro utilizará a comunicação incessantemente, seja para estimular, criticar, influenciar e principalmente para ouvir os liderados. O autor acrescenta que "a comunicação é um processo bilateral no qual os líderes ouvem, esperam por feedback e novas idéias e são guiados pela necessidade de estimular e influenciar, não de comandar e controlar".

$\mathrm{Na}$ situação implementação de nova rotina no serviço foi o comportamento dos enfermeiros avalia o desempenho do membro da equipe de enfermagem frente a execução de um procedimento que ocorreu com maior freqüência e a conseqüência decorrente foi implementação adequada de nova rotina na unidade.

Frente a esses dados, acreditamos que os enfermeiros participantes adotaram o estilo de liderança determinar $\left(E_{1}\right)$ pois, fica claro a necessidade de supervisão rigorosa na implementação de novas atividades no serviço.

O comportamento tenta promover mudanças no comportamento do membro da equipe de enfermagem foi o que obteve maior freqüencia na situação conduta profissional inadequada. As conseqüências oriundas deste comportamento foram: melhoria da produtividade do trabalho da equipe de enfermagem e demissão do membro da equipe de enfermagem.

O desempenho dos liderados é uma das responsabilidades do líder, baseados nas experiências com a Liderança Situacional, HERSEY \& BLANCHARD ${ }^{9}$ identificaram dois ciclos diferentes que o líder pode utilizar para mudar ou maximizar o nível de maturidade dos liderados.

Quando o enfermeiro deseja aumentar o nível atual de maturidade do elemento da equipe de enfermagem em relação a uma determinada tarefa, ele aplica o ciclo de desenvolvimento. Segundo HERSEY $\&$ DULDT $^{10}$ o enfermeiro precisa responder várias questões para iniciar o ciclo de desenvolvimento. A primeira seria: Qual o comportamento que desejo influenciar no elemento da equipe de enfermagem? Após o enfermeiro determinar o comportamento a ser 
influenciado, por exemplo a execução de uma sondagem vesical de demora, a próxima questão está relacionada com o desempenho do elemento da equipe de enfermagem naquele momento, ou seja, como é a capacidade e disposição daquela pessoa nesta tarefa. O enfermeiro poderá perguntar sobre essa questão para o elemento e/ ou observá-lo numa ocasião oportuna. Desta forma, o enfermeiro traça um panorama do nível de maturidade desta pessoa, ele realiza o diagnóstico da maturidade dessa pessoa naquela tarefa específica. Para finalizar, o enfermeiro determina até que ponto o nível de maturidade do elemento em questão deve ser desenvolvido.

Para HERSEY \& BLANCHARD ${ }^{9}$ se um líder quer influenciar um liderado que não tem capacidade e nem disposição (nível de maturidade $\mathrm{M}_{1}$ ) em relação a uma determinada tarefa, ele deve iniciar o ciclo de desenvolvimento orientando, supervisionando e controlando de perto o comportamento do liderado (estilo de liderança determinar). Entretanto, se o liderado não tem capacidade mas está disposto em realizar a tarefa (nível de maturidade $\mathrm{M}_{2}$ ) o líder pode iniciar o ciclo orientando e dando apoio ao liderado (estilo de liderança persuadir). Por outro lado, se o liderado é capaz mas não está disposto em executar a tarefa (nível de maturidade $\mathrm{M}_{3}$ ) o líder terá que enfrentar um problema motivacional; neste caso ele deverá iniciar o ciclo utilizando o comportamento de apoio (estilo de liderança compartilhar) para encorajar o liderado na realização da tarefa. Finalmente, se o liderado tem capacidade e disposição para execução da tarefa (nível de maturidade $\mathrm{M}_{4}$ ) o líder poderá simplesmente delegar as responsabilidades, pois ele sabe que o liderado irá desempenhar-se a contento, ou seja, não existe a necessidade de aplicar o ciclo de desenvolvimento.

Na maioria das vezes que o enfermeiro tiver que orientar uma nova atividade, ou quando o elemento da equipe de enfermagem está iniciando sua prática na enfermagem ou ainda quando o enfermeiro deseja maximizar o nível de maturidade do elemento em questão, com certeza estará envolvido com o ciclo de desenvolvimento.

Quando um líder perceber que houve regressão no nível de maturidade de um liderado em relação a uma tarefa específica, ele deve empregar o ciclo de regressão.

Os autores da Liderança Situacional colocam que o líder ao empregar o ciclo de regressão deverá dar um passo de cada vez. Se o estilo de liderança atual do líder é delegar $\left(E_{4}\right)$ e ele perceber que o desempenho do liderado regrediu em relação a uma determinada tarefa, o líder deverá retornar ao estilo compartilhar $\left(\mathrm{E}_{3}\right)$ e ajudálo a solucionar os problemas.

Assim, "se estivermos adotando um comportamento de apoio, mas não de direção com uma pessoa $\left(E_{3}\right)$ e seu desempenho começar a declinar, deveremos regredir ao estilo persuadir $\left(\mathrm{E}_{2}\right)$, continuando a incentivar a comunicação bilateral, mas ao mesmo tempo fornecendo mais direção. Se estivermos adotando um comportamento de tarefa e de relacionamento alto $\left(E_{2}\right)$ e ocorrer declínio de desempenho, teremos que voltar para determinar, reduzindo o apoio e aumentando a direção e supervisão $\left(\mathrm{E}_{1}\right)$. Tanto no ciclo regressivo como no de desenvolvimento é preciso ter o cuidado de não saltar de delegar $\left(E_{4}\right)$ para persuadir $\left(E_{2}\right)$ ou determinar $\left(\mathrm{E}_{1}\right)$ ou no caso inverso de determinar diretamente para compartilhar $\left(\mathrm{E}_{3}\right)$ ou delegar",

O comportamento dos enfermeiros delega a resolução do problema para a equipe de enfermagem foi o que ocorreu com maior freqüência na situação falta de recursos humanos; as conseqüências resultantes deste comportamento foram: resolução do problema e realização da assistência de enfermagem.

O estilo de liderança empregado pelos enfermeiros foi o delegar $\left(\mathrm{E}_{4}\right)$. Este estilo é apropriado para liderado com nível de maturidade alto $\left(\mathrm{M}_{4}\right)$, ou seja, pessoa que tem capacidade e disposição frente a determinada atividade; o líder pode ainda identificar o problema mas, o liderado traçará alternativas de solução decidindo como, quando e onde implementar a solução do problema.

O comportamento dos enfermeiros ouve a equipe de enfermagem sobre os problemas pessoais e profissionais enfrentados na unidade foi o único que ocorreu na situação falta no serviço e a conseqüência decorrente foi melhoria da produtividade do trabalho da equipe de enfermagem. Mais uma vez, ao nosso ver, fica claro a importância da comunicação no processo de liderar.

GALVÃO et al. ${ }^{8}$ compreendem "a comunicação como um recurso para o sucesso da liderança exercida pelo enfermeiro pois permite a esse profissional o desempenho de suas ações através de interrelações com o cliente, a instituição, a equipe médica e o pessoal de enfermagem, buscando a melhoria da qualidade da assistência prestada".

Ao nos reportarmos ao conjunto dos comportamentos adotados pelos enfermeiros nas situações investigadas podemos afirmar que estes profissionais empregaram estilos de liderança mais diretivos, ou seja, o determinar $\left(E_{1}\right)$ ou persuadir $\left(E_{2}\right)$. Esses dados coincidem com os encontrados no estudo de GALVÃ $\mathrm{O}^{6}$, no qual a autora analisou o estilo de liderança exercido pelo enfermeiro de unidade de internação cirúrgica com o pessoal auxiliar de enfermagem em seis categorias de atividades assistenciais. Os resultados evidenciaram que estes profissionais "têm se dedicado aos estilos de liderança mais diretivos, orientando, portanto, seu comportamento sobretudo para a tarefa, sugerindo-nos que o pessoal auxiliar tem apresentado 
nível de maturidade baixo e baixo a moderado ou então que os enfermeiros têm utilizado inadequadamente o estilo gerencial".

GALVÃO ${ }^{6}$ ainda analisou o estilo de liderança que o enfermeiro de unidade de internação cirúrgica deveria adotar em relação ao nível de maturidade do auxiliar de enfermagem frente as mesmas categorias de atividades assistenciais. Os sujeitos pesquisados (enfermeiros e o pessoal auxiliar de enfermagem) indicaram os estilos de liderança $\mathrm{E}_{3}$ (compartilhar) e/ou $\mathrm{E}_{4}$ (delegar), ou seja, estilos participativos, sugerindo que os liderados investigados apresentavam nível de maturidade moderado a alto $\left(\mathrm{M}_{3}\right)$ e/ou alto $\left(\mathrm{M}_{4}\right)$.

Em contrapartida, WOLF ${ }^{19}$ desenvolveu um estudo para avaliar um programa de Educação Continuada, cujo propósito consistia em ensinar aos participantes a aplicação da Liderança Situacional na sua prática profissional. Participaram deste programa 144 enfermeiros, foi realizado pré e pós teste para verificar mudanças nos estilos de liderança adotadas pelos sujeitos.

Assim, no pré-teste 72 sujeitos (50\%) empregavam o estilo de liderança persuadir $\left(\mathrm{E}_{2}\right), 60$ enfermeiros $(41 \%)$ o estilo compartilhar $\left(\mathrm{E}_{3}\right), 8$ sujeitos $(5 \%)$ o estilo determinar $\left(E_{1}\right)$ e $4(3 \%)$ o estilo delegar $\left(\mathrm{E}_{4}\right)$. Após conclusão do programa de Educação Continuada foi efetuado o pós-teste, sendo que 76 sujeitos (53\%) adotaram o estilo de liderança compartilhar $\left(\mathrm{E}_{3}\right)$, 40 enfermeiros (27\%) o estilo persuadir $\left(\mathrm{E}_{2}\right), 20$ sujeitos $(14 \%)$ o estilo delegar e $8(5 \%)$ o estilo determinar $\left(E_{1}\right)$, observamos que os participantes deste estudo passaram a utilizar mais os estilos participativos, ou seja, o compartilhar $\left(\mathrm{E}_{3}\right)$ ou o delegar $\left(\mathrm{E}_{4}\right)$.

Frente ao exposto, podemos afirmar que a Liderança Situacional pode ser utilizada como embasamento teórico para fundamentar a habilidade de liderar do enfermeiro no contexto hospitalar com vistas a melhoria da qualidade da assistência prestada ao paciente/cliente e possibilitar o desenvolvimento do potencial da equipe de enfermagem.

\section{4 - CONSIDERAÇÕES FINAIS}

Com a aproximação do século XXI, mudanças cada vez mais rápidas e complexas ocorrem, bem como o surgimento de novas tecnologias. Nesse cenário, entendemos que o enfermeiro deverá desempenhar uma gerência inovadora, orientada para as transformações com vistas a melhoria da qualidade da assistência de enfermagem prestada ao paciente/cliente, proporcionando maior satisfação para a equipe de enfermagem e o alcance dos objetivos organizacionais.

Assim, entendemos que a liderança e a comunicação são estratégias que possibilitam ao enfermeiro implementar as mudanças requeridas.

Acreditamos que os programas de Educação Continuada devem capacitar o indivíduo para enfrentar mudanças levando em consideração as necessidades dos profissionais que atuam na enfermagem e os propósitos da organização.

Ao nosso ver, investimentos na capacitação para o exercício da liderança é fundamental para que o profissional enfermeiro tente viabilizar mudanças na sua prática diária, de modo compartilhado com o grupo com o qual trabalha em conjunto, desenvolvendo neste habilidades para o exercício da liderança situacional e promovendo maior maturidade nos liderados a fim de compartilharem decisões relativas à prática profissional.

\section{LEADERSHIP AND COMMUNICATION: ESSENTIAL STRATEGIES FOR THE MANAGEMENT OF NURSING CARE IN THE HOSPITAL CONTEXT}

Leadership and communication are strategies that enable nurses to improve the management of nursing care within the hospital context. The present study aimed at reporting a Continuing Education Program developed by nurses from a private hospital on leadership and communication and to present the application of situational leadership in their professional practice. The technique of critical incidents was applied in data collection. The subjects evaluated positively the contributions of the Program and authors found the viability of the application of situational leadership in nursing daily practice.

KEY WORDS: leadership, communication, continuing education in nursing

\section{LIDERAZGO Y COMUNICACIÓN: ESTRATÉGIAS ESENCIALES PARA LA GESTIÓN DE LA ASISTENCIA DE ENFERMERÍA EN EL CONTEXTO HOSPITALARIO}

El liderazgo y la comunicación son estrategias que posibilitan al enfermero promover el mejoramiento de la gestión de la asistencia de enfermería en el contexto hospitalario. El presente estudio tuvo como objetivos relatar un programa de educación continuada desarrollado con enfermeros de un hospital privado sobre liderazgo y comunicación y presentar la aplicación del 
Liderazgo Situacional en su práctica profesional. La técnica de incidentes críticos fue utilizada para la recolección de datos. Los sujetos participantes del estudio evaluaron positivamente las contribuciones del programa y los autores constataron la viabilidad de la aplicación del Liderazgo Situacional en el cotidiano de enfermería.

TÉRMINOS CLAVES: liderazgo, comunicación, educación continuada en enfermería

\section{ANEXO A}

PREZADO COLEGA,

Você participou do programa de educação continuada "Liderança e Comunicação: estratégias essenciais para o gerenciamento da assistência de enfermagem no contexto hospitalar". O objetivo principal desse programa consiste em desenvolver a liderança e a comunicação do enfermeiro no seu dia a dia de trabalho.

Apresentamos os conceitos-chave do modelo de liderança proposto por Hersey e Blanchard, denominado Liderança Situacional, e como o enfermeiro pode aplicá-lo na sua prática profissional, bem como conteúdo sobre comunicação verbal e não-verbal.

Nas próximas semanas será agendado um encontro entre os participantes do programa de educação continuada e os instrutores com a finalidade de avaliarmos as contribuições oriundas do mesmo (a sua participação é fundamental, contamos com você!).

Com o intuito de agilizarmos nosso encontro, por favor preencha o instrumento anexo e traga-o para discussão.

Agradecemos a sua colaboração e esperamos você no próximo encontro.

\section{REFERÊNCIAS BIBLIOGRÁFICAS}

01. DECRANE JUNIOR, A.C. Um molelo constitucional da liderança. In: HESSELBEIN, F. et al. O líder do futuro. Trad. por Cyntia Azevedo. São Paulo: Futura, 1996. Cap. 25, p. 249-55.

02. DELA COLETA, J.A. A técnica dos incidentes críticos: aplicações e resultados. Arq. Bras. Psicol. Apl., Rio de Janeiro, v. 26, n. 2, p. 35-58, abr/jun. 1974.

03. FÁVERO, N. O gerenciamento do enfermeiro na assistência ao paciente hospitalizado. Ribeirão Preto, 1996. 92p. Tese (livre-docência) - Escola de Enfermagem de Ribeirão Preto, Universidade de São Paulo.

04. FERRAZ, C. A transfiguração da administração em enfermagem: da gerência científica à gerência sensível. Ribeirão Preto, 1995. 248p. Tese (doutorado) - Escola de Enfermagem de Ribeirão Preto, Universidade de São Paulo.

05. GALVÃO, C.M. Liderança do enfermeiro de centro cirúrgico. Ribeirão Preto, 1990. 69p. Dissertação (mestrado) - Escola de Enfermagem de Ribeirão Preto, Universidade de São Paulo.

\section{1- Dados Gerais}

Idade: Sexo: Faculdade:

Instituição que trabalha:

Unidade de trabalho (local):

Tempo de atuação neste local:

2- Questão relativa a utilização da Liderança Situacional no desenvolvimento do trabalho do enfermeiro no contexto hospitalar

Pense nas vezes que você estava trabalhando no hospital. Recorde situações em que você estava desenvolvendo sua prática profissional (atividades assistenciais; administrativas e/ou educativas) juntamente com o pessoal auxiliar de enfermagem (técnicos, auxiliares e atendentes de enfermagem). Agora, pense nas situações que você utilizou os conceitos-chave da Liderança Situacional para o desenvolvimento do trabalho na sua unidade de atuação.

(Por favor, relate de forma detalhada todas as situações que recordar).

- Descreva exatamente qual foi a situação, o que ocorreu e o que resultou desta situação.

06. GALVÃO, C.M. Liderança situacional: uma contribuição ao trabalho do enfermeiro-líder no contexto hospitalar. Ribeirão Preto, 1995. 117p. Tese (doutorado) - Escola de Enfermagem de Ribeirão Preto, Universidade de São Paulo.

07. GALVÃO, C.M. et al. Liderança Situacional: um modelo para aplicação na enfermagem brasileira. Rev. Esc. Enfermagem USP, v. 31, n. 2, p. 227 36, ago. 1997.

08. GALVÃO, C.M. et al. A liderança do enfermeiro no século XXI: algumas considerações. Rev. Esc. Enfermagem USP, v. 32, n. 4, p. 302-6, dez. 1998.

09. HERSEY, P.; BLANCHARD, K.H. Psicologia para administradores: a teoria e as técnicas da liderança situacional. Trad. por Edwino A. Royer. São Paulo: Pedagógica e Universitária, 1986.

10. HERSEY, P.; DULDT, B.W. Situational leaderchip in nursing. California: Appleton \& Lange, 1989.

11. KOUZES, J.M.; POSNER, B.Z. O desafio da liderança. Trad. por Ricardo Inofosa. 2. ed. Rio de Janeiro: Campus, 1997.

12. KURCGANT, P. Educação Continuada: caminho para a qualidade. Rev. Paul. Enfermagem, v. 12, n. 2, p. 66-71, maio/ago. 1993. 
13. MENDES, I.A.C. Enfoque humanístico à comunicação em enfermagem. São Paulo: Sarvier, 1994.

14. NOGUEIRA, M.S. Incidentes críticos da passagem de plantão. Ribeirão Preto, 1988. 109p. Dissertação (mestrado) - Escola de Enfermagem de Ribeirão Preto, Universidade de São Paulo.

15. PIMENTEL, M. Problemática da educação continuada nas instituições de saúde. Rev. Paul. Enfermagem, v. 10, n. 2, p. 72-4, maio/ago. 1991.

16. SILVA, M.J.P. Comunicação tem remédio: a comunicação nas relações interpessoais em saúde. $2^{\circ}$. ed. São Paulo: Gente, 1996.
17. TREVIZAN, M.A. Liderança do enfermeiro: o ideal e o real no contexto hospitalar. São Paulo: Sarvier, 1993.

18. TREVIZAN, M.A. et al. Liderança e comunicação no cenário da gestão em enfermagem. Rev. Latino-Am. Enfermagem, v. 6, n. 5, p. 77-82, dezembro 1998.

19. WOLF, M.S. Changes in leadership styles as a function of a four-day leadership training institute for nurse managers: a perspective on continuing education program evaluation. J. Contin. Educ. Nurs., v. 27, n. 6, p. 245-252, November/ December 1996. 